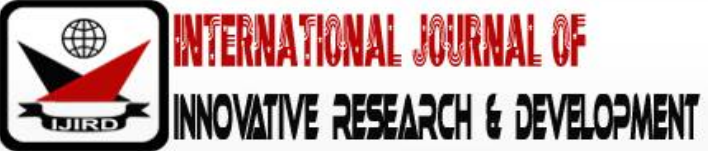

ISSN 2278 - 0211 (Online)

\section{Effective Use of Typography in Print Media Advertising, Case Study: Sekondi-Takoradi Metropolitan Assembly, Ghana}

G. Brako-Hiapa
Senior Lecturer, Department of Graphic Design Technology,
Takoradi Technical University, Ghana
Ernest Taylor Nkrumah
Senior Technician, Department of Graphic Design Technology,
Takoradi Technical University, Ghana

\begin{abstract}
:
The primary focus of the study was on the effective use of typography in print media advertising. It has been observed that the visual perception of the use of typography in most communication design materials is sometimes overlooked by majority of graphic designers. In view of this, the study sought to examine, analyse and interpret the effective use of typography in print media advertising. Similarly, it sought to study and analyse the visual perception and emotional response to typography in print media advertising. The research approach was qualitative that generated narrative or textual descriptions of the study. Mixed methods research was employed and the instruments used in gathering data were direct observation and interview. Population for the study therefore was print media adverts found or mounted on the streets of Takoradi market-circle, Effia-Kwesimintim, and Sekondi in Western Region of Ghana. The findings of the study revealed that typography is an effective discipline with basic guidelines, elements, principles and factors to follow when designing to enhance effective communication in print media for an outdoor advertising. However, when designers resort to making decisions on typography and do not adhere to the basic rules, principles and factors for designing it has a negative impact on the use of typography for effective communication. It is recommended that contemporary graphic designers should explore and understand innovative mechanisms and basic principles for typographic design when developing print media for outdoor advertisement in order to positively draw attention of the viewer to a particular advertisement and also convey a particular message for effective communication.
\end{abstract}

Keywords: Advertising, graphic designers, effective communication, print media, typography, visual perception

\section{Introduction}

The feats of typography have been used by ancient civilisations of the world to represent ideas which were presented in forms of symbols and images which later evolved into alphabets and phonographic writing, which led to the development of various typographic systems. Typography is one of the oldest art forms in the world, and one that has remained important even through the move from the print to the digital age (Mark, 2011). Typography is everywhere we look, it is in the books we read, on the website we visit, even on street signs, bumper stickers, and product packaging in everyday life. It is worth noting that typography is one of the most essential and satisfying components of graphic design. Hence, irrespective of how experienced designers have become, it is always helpful to refresh the mind about the principles of typography for effective communication. Many a time designers try to learn the basics and specific origin of a particular font or the structure of a typeface with the view to enrich the meaning of their creative works. They study the nitty-gritty of the art since typography is not a straightforward practice. Ovsyannykov (2018) reported that majority of designers are able to identify and take into consideration complex composition of a typeface that consists of specific vocabulary, accurate measurements, and central specifications.

Typography is explained by Squire, Forssman, \& Willberg (2006) as the arrangement and organization of written words in such a way as to facilitate communication of a content mechanically. Squire et al emphasised that though typography traditionally refers where letter forms are handset and printed from physical metal type, the scope of typography has expanded due to current development of digital technology most especially the use of personal computers and the evolution of the internet. Byrne (2004) on his part viewed typography as the arrangement of letters and words that conveys information and meaning. Childers and Jass (2002) also illustrated typography as the art, or skill, of designing communication by means of the printed word. To them these letters are used to communicate ideas therefore it can take on a variety of forms due to its variation in the elements of the letter's design. The import of these definitions stems from 
the fact that typography is the conscious and effective use of typefaces and fonts in a clear manner that communicates a message to a targeted audience.

Chapman (2019) differentiated between typeface and font by establishing that a typeface is a set of typographical symbols and characters. That is, a typeface has letters, numbers, and other characters and a font, on the other hand, is traditionally a complete character set within a typeface, often of a particular size and style. Birkner (2018), in support of Chapman's view, mentioned that a typeface is also known as font family and it is a set of characters that share common design features. This single typeface is represented by a specific weight, style, condensation, width, slant, italicization, ornamentation, and designer or foundry, but not by size. (e.g. 'ITC Helvetica Neue Condensed Bold Italic' is a different typeface from 'ITC Helvetica Neue Condensed regular Italic' or 'ITC Helvetica Neue Condensed Bold').

In graphic design, the use of typography can vehemently affect how people respond to a design. The selection and consistent use of a preferred typeface is as important as the use of graphics, colours and images. Considerably selecting the right font allows the graphic designer to evoke a particular feeling as well as fit a certain style or format. Typography is essentially a blend of art and science meant to serve a functional purpose. As a result, the competent use of typography commands the attention of the audience and communicates a key concept and eventually motivates them to react.

Several researchers have embarked on experiments and explored the effects of typography. The Graphic Composition (2017) reported that when good typography is used, the audience frown less and perform creative cognitive tasks better afterwards. The Graphic Composition identified and also focused on determining factors that make typography most effective which includes the skilful use of fonts for onscreen purposes. In furtherance it explained that visual fatigue from reading off a computer screen can be attributed to awkward character rendering, poor choice of line length and other typographical elements. This emphasizes the core significance a good typography offers in helping to reduce eye fatigue and eye strain for readers. The implication here is that typography involves the art of arranging letters and texts in a way that makes the copy legible, clear, and visually appealing to the reader. The font style, appearance, and structure chosen aim to elicit certain emotions and convey specific messages. In other words, it is typography that brings the text to life.

Typography is a valid discipline with basic rules, principles and parameters to follow for effective communication. Components such as readability, legibility and comprehension of type, typography and colour, as well as typography aesthetics need to be explored since they are crucial pieces of the puzzle when creating an effective communication. Nielsen (2015) emphasized that readability measures the intricacy of the words and sentence arrangement in a piece of content and it is usually described as the reading level needed to easily read a text. To Nielsen, the assumption behind this measurement is that complex sentences are tougher to analyse and read than simpler ones. On the other hand, Scarborough (2015) justified that readability is the ease with which a written text can be understood by a reader. Scarborough buttressed the understanding of readability as an appropriate choice of fonts, contrasting colours and varied sizes of fonts used for different levels of importance in designing a message. The context of readability also brings into line legibility for which Darwish (2010) referred to it as the clarity of form, the way a text is presented physically on paper and affects all readers regardless of the purpose of reading. Darwish further explained that typographical features such as typefaces, point sizes, margin width, text width, line spacing, letter spacing, and paper size determine the degree of legibility which can facilitate or hinder accessibility of the information contained in a given text.

The role colour plays in typography cannot be underestimated as it helps designers to carefully set up font palette needed to complete a design. Ambrose \& Harris (2011) asserted that colour in typography is seen as the cornerstone that serves as the logical and visual platform with the central view of creating a clear distinction or contrast between the text elements and the substrate. Harkins (2011) referred to typography and colour as a term known as typographic colour which is used in design to show the overarching quantity or texture of a text. Ambrose and Harris (2010) supported Harkins' view by reiterating the fact that typographic colour is the density of the textural coverage on a page that effectively adorns a design, so as to bring the text to life.

Colour is one of the most essential and powerful tools of a designer. Therefore, the effective use of typography principles has helped designers to carefully set up font palette needed to complete a design. Designers in putting together a font palette (colour schemes), delve into the colour theory to determine the right colours intended for a particular design. Ambrose and Harris (2008) mentioned that the variation of fonts and their weights available to the artist provides a palette of varying colour strength that when used creatively, can improve and impact the look of a page and design. This gives an elaborate artistic impression of colour in typography as one of the most important decisions to make when differentiating a print media advertising to stand the test of time. Making an impression of font type, size, contrast and spacing is all part of a delicate balancing act that when done right in conjunction with colour will create a positive experience for the audiences. The significant effect of colour on typography enables the font and background colours in a more efficient way (Waggener, 2018).

Choosing the right typeface becomes a purely aesthetic exercise which helps the audiences to understand the principles of colour, type and mark. Sayegh (2018) affirmed that when the right thought is given to the psychology behind the design, the best work tends to come out with differentessential styles for which the emotional responses of the audiences are based. Similarly, Nikolov (2017) viewed that bringing up positive attitude in audiences with brand or print media advertising with pleasing designs rests with typography and these aesthetic designs of products have a better influence on how audiences think and feel. Nikolov's explanation revealed how aesthetic design affects the long-term attitude on products and even the audiences. In this regard, typographic aesthetics by both authors to a larger extent, sees a major relation between the minds of audiences and principles of aesthetic designs of colour, type and mark which matter not only to make the first impression, but also to keep strengthening the bond with the audiences. Thorlacius (2007), on the other hand, disclosed that typography aesthetics plays an important role in supporting the content and the 
functionality, in appealing to the taste of the target audience, in creating the desired typography. To achieve a great aesthetic design in typography, the content and functionality of typographic factors determine the comprehension of legibility and readability, such as the font colour, design, size, spacing, leading, contrast, line length, paragraph alignment, justification and background. Typography in this context requires thought and understanding of these basic components that bond function with aesthetics.

The role of typography is very important in creating advertisements, logos, and other documents. In advertising, typography can communicate or reinforce messages, add to a document's personality and even influence emotions. Evidence suggest that type can communicate meaning outside of the words the typeface represents, helping to support a product or brand message (Brumberger, 2004). In support McCarthy and Mothersbaugh (2002) opined that typography is one crucial element of graphic design that contributes to the all-embracing beauty of visual communication. Schriver (1997) reiterated that typography can be utilized to set a mood or a structure, promote readability and navigation, give clues about the nature of the document, convey how a passage of text is to be used, and even reveal important elements in the passage.

The understanding of typography by graphic designers in Ghana specifically in the field of font psychology, and how different typefaces can provoke different emotions, is key to figuring out which typeface one needs to use to communicate a particular message to a targeted audience. In fact, the typeface a designer chooses or uses to compose a typography for a design of any graphic or advertising project could enhance communication to a large extent. Of course, choosing the perfect font for typography is not always as simple as it seems. Not only does the designer have to find a font that will help his thoughts stand out in the marketplace, but there is also a need to browse through thousands of potential pre-existing fonts before considering whether to choose a custom option for a particular project.

Typography has long been a vital part of promotional material and advertising. Designers often use typefaces to set a theme and mood in an advertisement. As print media advertising has advanced, it is clear that major designs are driven by big powerful imagery. However, the graphic designer cannot ever lose sight of the fact that typography is the lynchpin that holds effective design together. Many factors, such as font selection, appropriate measure, typographic size hierarchy and typographic weight hierarchy guide users through the site experience. Typography creates visual logic and directs users to the many messages that marketers need to deliver. With all the resources put into message development, understanding how these measures of typography are presented in print media advertising is critical (Purely Branded, 2019).

The study looks at some typographic elements which influence the presentation of messaging on print media advertising in Ghana. The focus of the study is therefore to explore the effective use of typography in the print media advertising such as billboards and posters mounted on the principal streets of Takoradi market-circle, Effia-Kwesimintim, and Sekondi in the Western Region of Ghana. The specific objectives of the study are to examine, analyse and interpret the effective use of typography in advertising. Similarly, the study is to analyse the extent to which typography used influences visual perception and emotions of communication in advertising.

This study is based on the fact that typography ensures that the message content of every communication design product is effectively disseminated. It also looks at the perception and feelings with the visual communication. Barry (2005) established that a good use of type in a graphic design work attracts a reasonable amount of appreciation. This amount of appreciation is characterised by perception theory. This perception theory by Barry combines a neurological research and psychological principles applied to visual communications. Again, it maintains the emotions involved in the processing of visual communications and specifically targets visual communication as paralleling perceptual process dependent on primary emotion-based systems of response. Barry emphasised that perception theory has discovered that a respondent's visual processing is unconscious, leading to reactions based on emotions. This theory is imperative for various forms of communications research, precisely those seeking respondent's reaction to visual media. As most messages are communicated through visual media, it is vital to appreciate how individuals interpret those messages. The eyes and brain play a large role in understanding, collecting visual information through the eyes and then seamlessly interpreted by the brain, letting the brain to unconsciously absorb emotionally (Barry, 2005). A similar opinion shared by McLeod (2008) established that for one to comprehend easily the core concept of a typography, it is important to read or absorb the writing as a whole rather than isolating the type or words individually.

\section{Materials and Methodology}

The materials for the study are sampled print media adverts found or mounted on the commercial streets of Takoradi market-circle, Effia-Kwesimintim, and Sekondi in Western Region of Ghana. The study was limited to billboards, banners and posters. The study is purely Qualitative which generated narrative or textual descriptions of the phenomena under study. Qualitative studies offer prospects for the exploration and description of phenomena in situ via multiple data sources (Baxter and Jack, 2008). The descriptive method, content analysis approach and phenomenological study were adopted and relied on observation checklist and interview for the data. The descriptive method was used to record, describe, analyse and interpret secondary data from books (Best, 1981). This provided evidence on what has been done already on the study. The content analysis method on the other hand, as asserted by Leedy (2005) was adopted for description of the body of material for study to give precise definitions and descriptions of the characteristics we were looking for. This helped in the appreciation of the print media adverts through critical observation of the effective use of typography, a description of the compositional structure, expressive and communicative qualities, qualities of fundamental aspects of legibility, readability, and analysing the aesthetics and emotional response portrayed in the adverts. 


\subsection{Sampling}

The main sample and sampling procedures adopted for the study were simple random sampling, purposive sampling, stage sampling and proportional stratified sampling. Simple random sampling was initially adopted to take shot of six hundred (600) print media products from the designated area of the scope. Several factors accounted for the choice of the print media products which include visibility, easy access and location. The study applied this technique because the population is a homogeneous group. Stage sampling which involves selecting the samples in stages, that is, taking samples from samples was used for selecting from the initial 600 print media products covered. With this technique, the study initially selected a good number of the shots taken. After careful examination and critical analysis of the pictures based on inherent and expressive qualities attached to them, 100 works were finally sampled for the study. The technique was adopted due to the large number of shots taken from.

With respect to interviews, purposive sampling was used to handpick three (3) professional graphic designers to assist in analysing the sampled works. Creswell (2007) stressed that the philosophical position of a study depicts how a researcher would purposefully select the participants and sites for the study. Since the nature of reality and knowledge about the phenomenon is paramount to determining the participants, the purposive sampling technique was used. The purposive sampling technique was adopted because of the type and quality of information needed and the participants are very knowledgeable to give the requisite information needed to understand the research problem. This sample size was considered since the study is essentially a qualitative study and its strength is not embedded in the numerical data gathered but in the quality of the information sought for in the research. The criterion for sampling the three (3) professionals was those into print media advertising and teaching graphic design. The reason is that the study concerns itself with print media advertising. Proportional stratified sampling was also employed to put the final sample of art works into different strata for appreciation. The technique is deemed appropriate because the sampled art works appeared in different art forms, characteristics and proportions.

\subsection{Data Collection}

The researchers visited the various locations where the billboards, posters and other print media adverts were mounted for critical observation on issues relating to the use of typography and other elements under study. Still shots and videos of the adverts were taken using a Digital Single Lens Reflex (DSLR) camera. The duration of each visit during which the observation was made lasted between 30 minutes and 1 hour. We then recorded what had been observed in a field note book which was later transcribed for the study. It took about two months to cover the geographical scope of the study. The phenomenon being looked for was all recorded in a field note book for later transcription.

Appointments were also made with three (3) professional graphic designers where we had the opportunity to interact with them and solicited information and their views, in connection with issues relating to typography based on the still shots and videos taken on the print media adverts. The duration of most interviews was long and the semistructured interview adopted allowed us and the participants to engage in a dialogue in real time. It also gave enough space and flexibility for original and unexpected issues to arise, which allowed us to investigate in more detail with further questions. We prepared an interview guide which consisted of a list of questions that allowed us to consider the range of issues that needed to be covered during the interviews. The guide included key questions or areas that reflect the demands of the main research questions. Open-ended and expansive questions were developed around the research aims to encourage participants to talk at length. The variables asked were meant to solicit and explore participants' thought and perception individually on the effective use of typography in print media adverts and the visual perception and emotional response they carry.

We also had the opportunity to visit locations where adverts were mounted with some consenting Professional Graphic designers as follow-ups for them to share their experiences. The interviews were recorded using a smartphone and later played back after leaving the field to extract and classify key concepts of responses which were transcribed into text. Quick notes were also taken where necessary to supplement some of the recorded material.

\subsection{Data Processing and Analysis}

The data was analysed by following both descriptive and interpretive phenomenological (IPA) data analysing procedures. Relevant and key concepts of findings were grouped into categories that reflect the various aspects of the research questions and the various meanings identified were used to develop an overall description for the study. The initial stage of the data analysis began with multiple close reading of the original transcript a number of times and making notes about the observations and reflections about the interview experience. The notes were later transformed into emerging themes. The next stage was seeking relationships and clustering of themes. At this point the connection between emerging themes was sought out, grouping them together according to conceptual similarities, and providing each cluster with a descriptive label. The categorization generated more themes that guided the development of the study. Some of the themes which do not fit well with the emerging structure or having a weak evidential base were dropped at this stage.

\section{Results and Discussion}

The results of the study are presented and analysed in qualitative descriptive form with the corresponding data retrieved in the form of pictures. The data collected was guided by the research questions put forward for the study to generate emerging themes to reflect the main objectives set out for the study. The emerging themes from the findings in effect are discussed under the following two main sub-headings:

- The effective use of typography in advertising

- Visual perception and emotional responses to typography in advertising. 


\subsection{The Effective Use of Typography in Advertising}

It is worth noting that typography is very important in creating advertisements since it communicates or reinforces messages, adds to a document's personality and even influences emotions. Squire, Forssman, \& Willberg (2006) explained typography as the arrangement and organization of written words in such a way as to facilitate communication of content. The explanation given here suggests that typography is a skill of designing communication which involves arrangement of letters and words to convey information and meaning. Typography is therefore considered to be a crucial element of graphic design that contributes to the overarching beauty of visual communication. The evidence here suggests that the determining factors that make typography most effective include the skilful use of fonts and arrangement of words. However, the findings revealed that some print media advertisements were carried blindly with unacceptable arrangements and use of fonts which have a negative impact on the effective usage of typography for effective communication. The most recurring characteristics identified were: -

- Crowded typography,

- Poor physical characteristics of Typography,

- Inappropriate use of fonts and space

- Ignoring readability in typography

\subsubsection{Crowded Typography}

It was observed that the concept and formation of typography semantics associated with certain fonts on billboards were overcrowded with typographic characters. A typical example is portrayed in Fig. 1. Majority of the fonts on this billboard were of the same size and optically of the same weight. Mostly every character was in the upper case, too many visual effects (drop shadows, outer glows, outline strokes), and above all the given space surrounding the entire typography was too small making every character to fight for space. Moreover, it was observed that, the arrangement of the key images of the billboard was struggling for prominence, considering the juxtaposition of the image supposed to be Jesus as against the image of the pastor. Also, the negative and positive spaces create conflict in the eyes of the viewer. The visual composition of the typography defies the law of emphasis and distance, and in the area that is supposed to show depth, most especially at the extreme left of the composition, the two subjects (figures) which are of the same size and intensity are placed on top of another.

Technically, the entire composition of Fig.1 lacks tracking, leading and kerning. Tracking which focuses on the letter spacing was abused because of the use of graphic effects most especially in the phrase 'STEPPING AHEAD AND 31'ST WATCH NIGHT'. The kerning job which is the spacing between the characters of the phrase '2019 MY YEAR WITH CHRIST'is not defined and though the colour scheme is optically calm, the outer glow from the background does not give a visual pleasing result. The leading which is the line spacing between the phrases '2019 MY YEAR WITH' and 'CHRIST' was not well arranged due to the intervals and the use of outer glows which in effect, affects reader comfort and easy comprehension. McLeod (2008) and Gregroy (1970) emphasised that for one to comprehend easily the core concept of typography, it is important to read or absorb the writing as a whole rather than isolate the type or words individually.

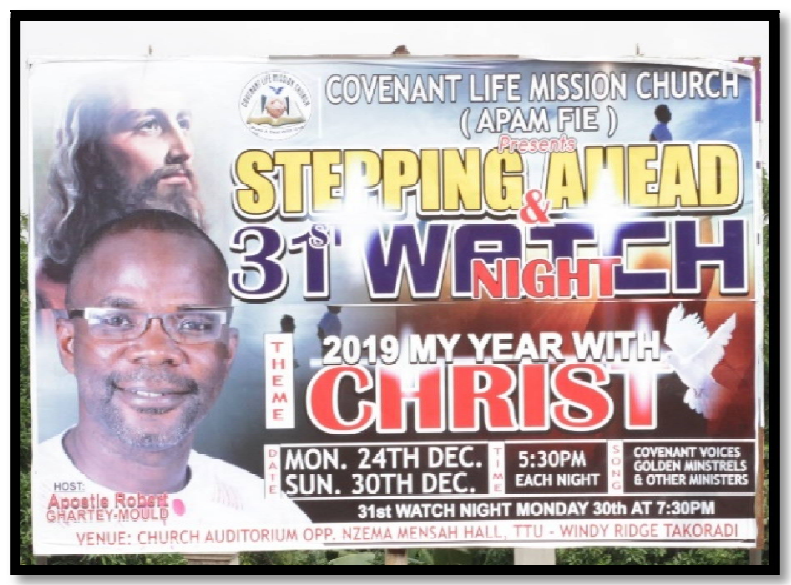

Figure1: Crowded Typographic Work

Photo Source: Researchers' Field Study, 2019

\subsubsection{Poor Physical Characteristics of Typography}

Another recurring negative effect observed was poor physical characteristics of typography. This entails the overly display of font with exaggerated typography which adversely affect reader comfort and effective communication. Example is Fig. 2 which shows the overly display of font with exaggerated typography which read 'Cross Over'. Hence, the typography is having overly exposed visual effects (reflective highlights) which make it difficult to read from a distance. The typefaces or fonts displayed have characteristics of negative impressions that may undermine delivery of a message to its viewers. Consequently, it is important to select an effective typeface that helps convey the meaning of a message clearly and effectively to the viewers. Furthermore, the typography on the left side of the poster appears to bleed at the edge of the entire design, and whereas the main subject or the focal point ('the Cross Over') turns to comprehend the primary message of the poster. The juxtaposition of the two main figures below, on the extreme right of the poster is not in symphony with the typeface on the left looking at the size and positioning of both images. Also, the colour link between 
these two components (the typeface and the two main images) is not well recognized, even though the artist tried to establish the physical characteristic (such as legibility) of the poster. However, the identification of the two main images for the poster was not readable based on the font size and font type used by the artist. Darwish (2010) referred to legibility as the clarity of form, to the way the text is presented physically on paper and affects all readers regardless of the purpose of reading. Contrary to Darwish's view the degree of typographical features such as typefaces, point sizes, margin width, text width, line spacing and letter spacing, do not facilitate effective communication of the information.

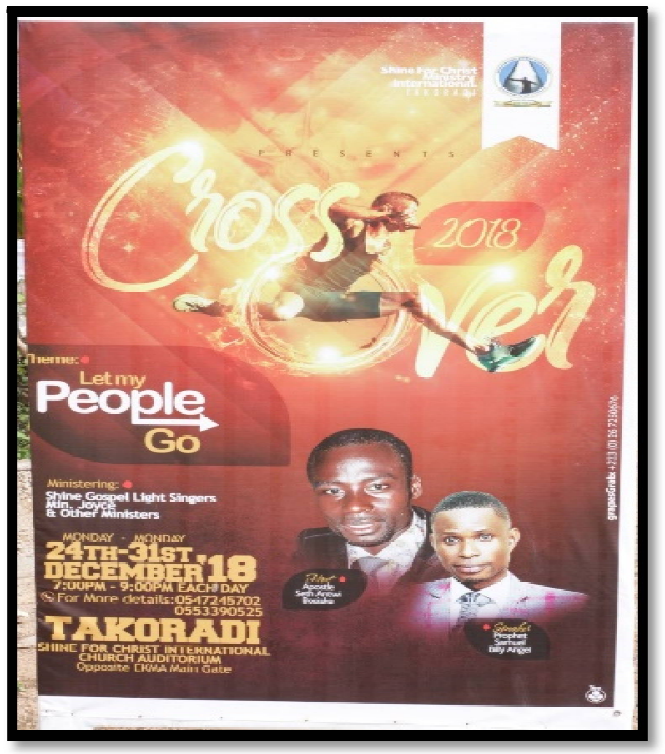

Figure 2: Poor Physical Characteristics of Typography

Photo Source: Researchers' Field Study, 2019

\subsubsection{Inappropriate Use of Fonts and Space}

Inappropriate use of fonts and space was also observed to have an impact on effective communication. Figure 3 shows unfavourable typographical gap between script italics fonts for typography that reads 'Free Admissions Free Admission Free Admission'. This font style is so slim that it makes reading difficult for a headline. Moreover, it has also been overshadowed with white outer glow making the text lose its weight and character. The three main images which are positioned at the centre of the poster appear to be extremely big which turns to make these images struggle for space, creating the illusion of overcrowding. The alignment of the entire typeface on the poster was not properly placed making the left side of the design to bleed at the edge. For example, the relation or placement between the typefaces, 'Mega International School' as against 'Admission in Progress for' illustrates the vigorous inconsistencies in the entire composition which adversely affect the aesthetics of the design which is to influence positive thought and feel of the audiences. Nikolov (2017) affirmed that bringing up positive attitude in audiences with brand or print media advertising with pleasing designs rests with typography.

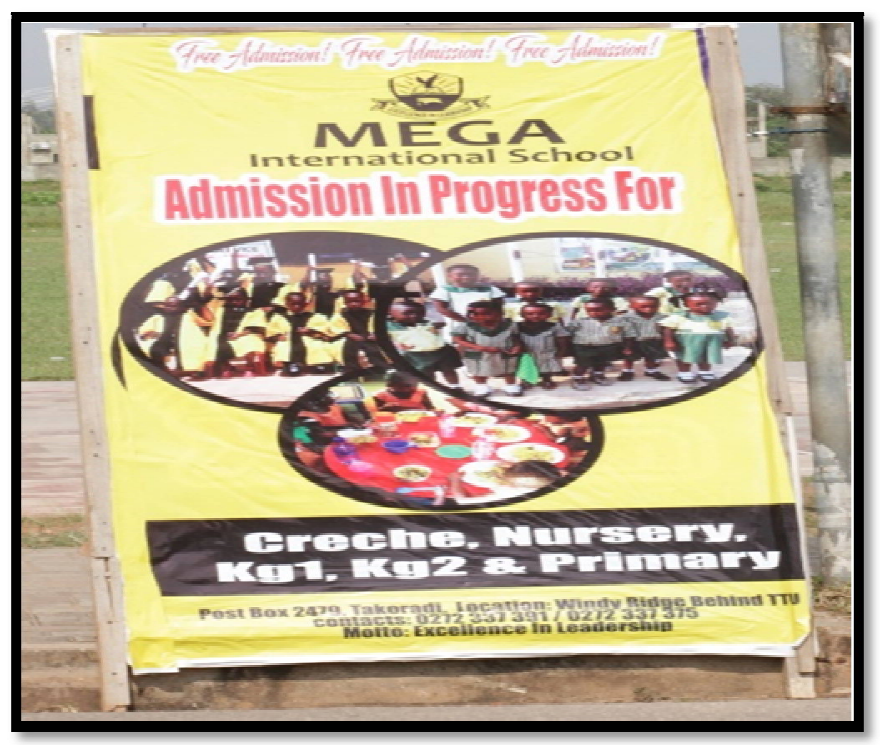

Figure 3: Inappropriate Use of Fonts and Space

Photo Source: Researchers' Field Study, 2019 


\subsubsection{Ignoring Readability in Typography}

The study also revealed that majority of the advertisement placed less importance on legibility and readability in typography. This implies that the way typographical elements such as typefaces, point sizes, margin width, text width, line spacing and letter spacing were rendered and presented physically in some instances did not enhance easy reading and understanding of messages. Scarborough (2015) described readability as the ease with which a written text can be understood by a reader. Scarborough further attributed readability to the appropriate choice of fonts, contrasting colours and varied size of fonts used for different levels of importance for each subsection. Unfortunately, in Fig. 4no importance was placed on the legibility and readability in typography. The varied sizes of fonts and colour used do not portray any sense of feeling to set a mood or a structure to attract audiences' response. The relationship between the used typefaces against audiences' response is relatively weak in the design and therefore affects effective communication of the message. Schriver (1997) and Guthrie (2009) asserted that typeface can be utilized to set a mood, promote readability and audience's responses in a pure design and visual communication perspective. Unfortunately, the lack of empirical evidence has left typeface out of the visual communication rhetoric, pinning type as less important in the applied field of typography in the print media advertising.

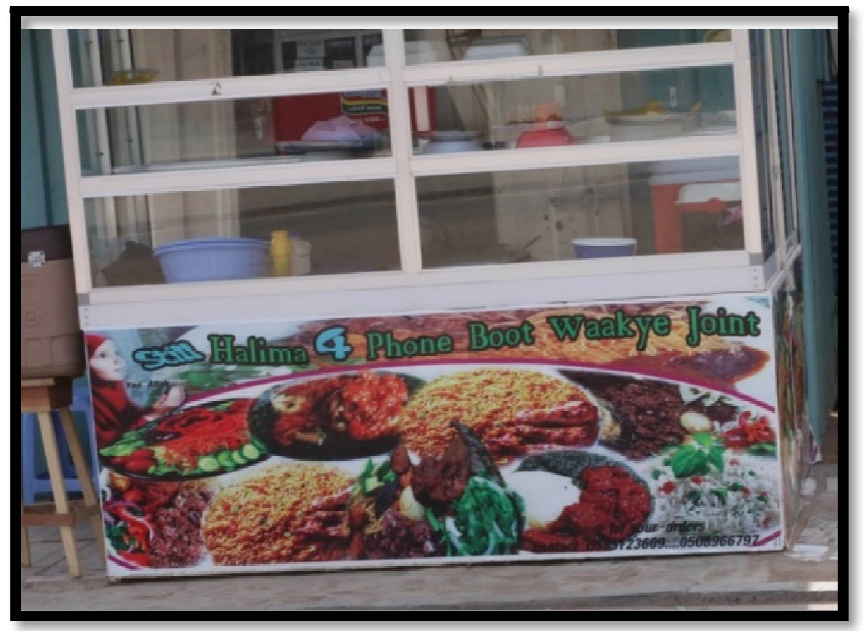

Figure 4: Ignoring Readability in Typography

Photo Source: Researchers' Field Study, 2019

\subsection{Visual Perception and Emotional Responses to Typography in Advertising}

The data retrieved on the factors affecting visual perception and emotional responses to typography in billboard and poster advertising is categorized and presented under eight clustered themes. Each theme is described and exemplified with pictorial extracts from the study and interpretative commentary. The emerging themes for discussion are:

- Relationship between typography and image to convey a message

- Use of the same typeface in varied sizes

- Combination of similar typefaces in different font styles

- Poor arrangement of typography on design

- Relationship between typography, colour and image

- Basic typography principles, tracking, kerning and leading.

- The emotion and personality trait of fonts and colour in typography

- Mismatch of Typography

\subsubsection{Relationship between Typography and Image to Convey A Message}

The existing theory of perception by Gregory (1970) established that typography (specifically fonts or typefaces) in advertising and design connotes visual perception and emotional responses. It was therefore observed that typography and design elements were handled perfectly in designs to drive audience responses. Some identified billboards displayed a good relationship between typography and image to convey a message and attract a reasonable amount of appreciation characterised by perception. Fig. 5 is one of the identified billboards exhibiting a good relationship between typography and image to convey a message. The general layout shows a great mastery of typographic design with white fonts and background. The typeface of 'ADONKO' is presented in Serif with 'ATADWE GINGER' also written in San-serif. These typefaces are encased in a stylish block of rectangles with gradient shades of black and green projecting them on top of the billboard. The design of the billboard is preceded with adlibbing female figure engulfed with red colour that creates a hue variation and sustainable interest for the viewer. The colours of the 'kente' dress worn by the female figure show a collaborating harmonic effect of the design. The imposing bottle of the 'Adonko' with pictorial evidence of 'atadwe' and ginger graces the focal point of the advertisement. This creates a link of communication between the female figure and the 'Adonko' bottle giving the composition a soothing feeling from the viewer's standpoint. The attributes of this billboard affirm Barry's (2005) view that a good use of type in a graphic design work attracts a reasonable amount of appreciation characterised by perception. 


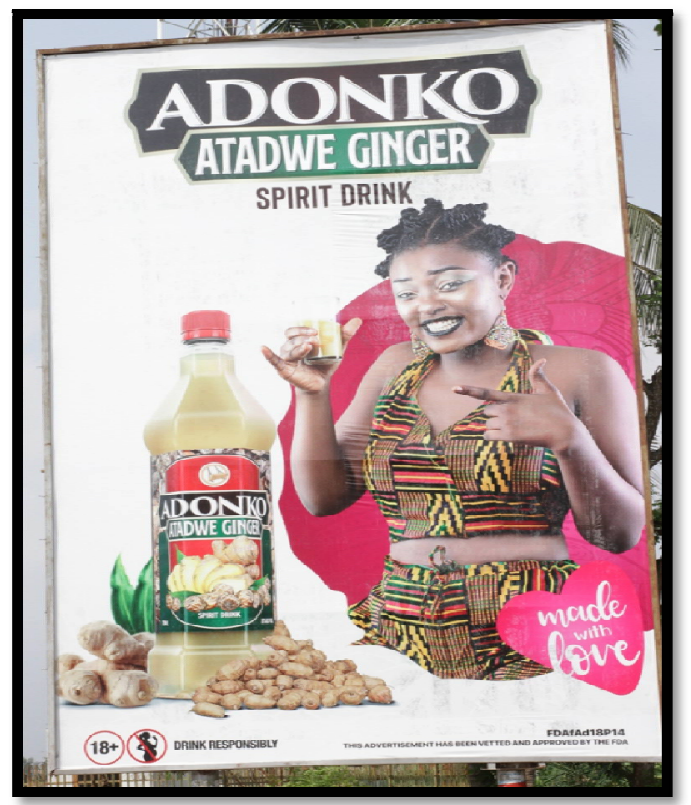

Figure 5: Adonkobill Board Exhibiting a Good Relationship between

Typography and Image to Convey a Message

Photo Source: Researchers' Field Study, 2019

\subsubsection{The Use of the Same Typeface in Varied Sizes}

The study observed effective use of the same typeface in varied sizes and typographic elements to achieve an efficient print media advertising design that conveys visual elements, emotional perception and feelings to its audience. Lynch and Horton (2019), Koch (2011), Bernazzani (2017) and Knight and Glaser (2012) all emphasised that a good visual communication of the message content of typography in advertising and design must have a strong perception, communication and aesthetic values. Figure 6 is a sampled design that portrays manipulation of emotional responses (feelings and reactions) through the effective use of fonts or typefaces to help the audience to better understand the messages. The white typeface 'It pays to talk' together with other related typefaces on the Vodafone billboard as against red background shows a great sense of contrast. In order to project the focal point of the billboard, emphasis is placed on "Talk for 1 minute, get 10 MB free data'. The drop shadow effects behind typefaces 'Talk for 1 minute, get 10 MB free data' give a stand out three-dimensional feel. There is coordination between the typefaces on the billboard suggesting a good use of the same typeface in varied sizes and effect in one work. Moreover, the billboard displays an effective communication of fonts and depicts hierarchy in typography. The presentation of good use of the same typeface in varied sizes and effect in the work makes this billboard an outstanding piece.

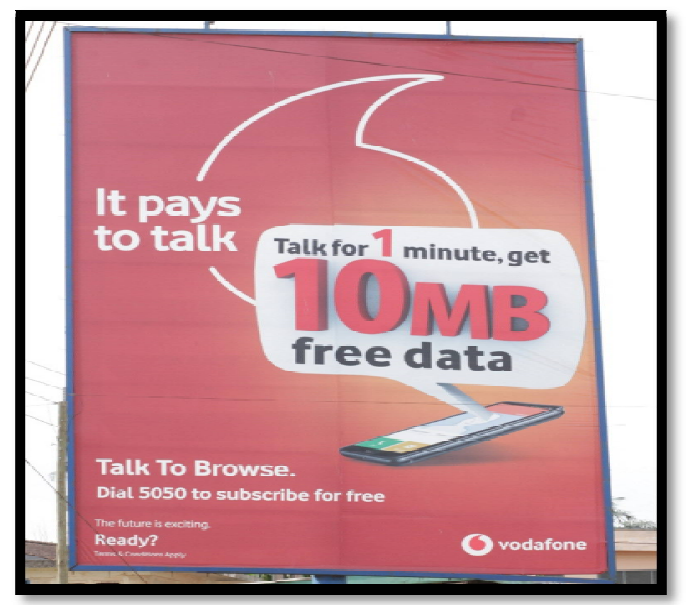

Figure 6: Billboard Showing a Good Use of the Same Typeface in Varied Sizes and Effect in One Work

Photo Source: Researchers' Field Study, 2019

\subsubsection{Combination of Similar Typefaces in Different Font Styles}

Fig.7 was one of the identified designs portraying a combination of similar typefaces in different font styles. It is a church poster domineering five male figures posing as church ministers coupled with typefaces in different font styles. Again, it has an insertion of a group picture beneath a caption under the church ministers. The poster has a darker background of purple colour with bolding caption 'My Royal Praise, 2018' written in golden typeface and a combination of similar white typefaces 'A reason to praise my Lord, Psalm 9:1-2' in different font styles. Emphasis is much placed on the 
golden typefaces and the male figures. The poster achieved its intended purpose of attracting the audience to the church programme through the design layout. Hence, the focal point to appeal to the perception and emotions of the audience was placed on the golden typefaces 'My Royal Praise, 2018' and the human figures. The inclusion of the 'Rate - Free' tag in the red circle button was strategic to seek audience attention since free things often appeal to majority of individuals.

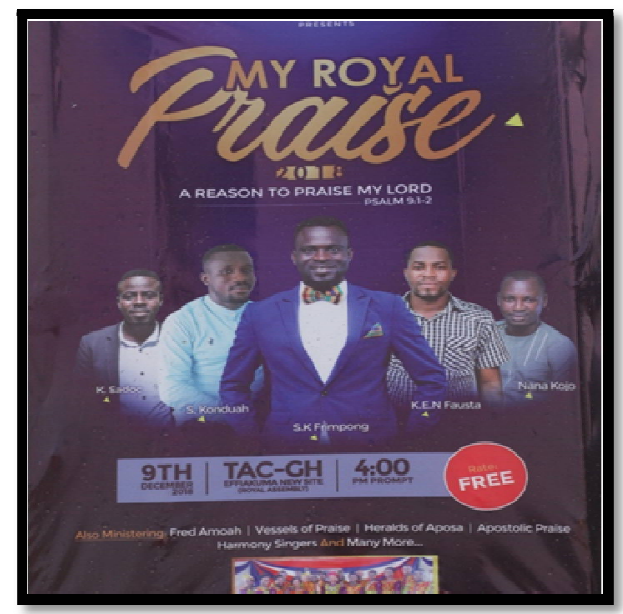

Figure 7: A Combination of Similar Typefaces in Different Font Styles Photo Source: Researchers' Field Study, 2019

\subsubsection{Poor Arrangement of Typography on Design}

The study revealed that typography was poorly rendered in some designs and did not have significant effect on its audience. Typography is quite simply the art and technique of arranging typeface for which depending on the context and purpose, it can be used for finest readability, impact and an artistic statement (Art times, 2014 and Koch, 2012). It is worth noting that typography, layout and graphic design are design elements that can be applied to the letters, texts and other forms like images, tables or other visual enhancements on a printed subscript to enhance typographic aesthetics for effective communication. Nikolov (2017) disclosed that pleasing designs with typography in print media advertising aesthetically bring up positive attitude in audiences. However, this attribute was lacking in some of the studied designs and therefore, did not drive the emotional responses of the viewer effectively. Sample of such designs is Fig. 8 which is a billboard displaying images of varied plastic containers (Polytanks) for public use. There is a slogan 'We are family!' written and some varied font sizes that identify the products being sold. The fonts and images in the composition are arranged haphazardly which clearly suggests inappropriateness in arrangement of typography on design. The haphazard arrangement of non-readable fonts on each plastic product shows inconsistencies in text alignment that makes it difficult for viewers to see and catch the feel of the design. Logically, this design drops down all the typographic variables that can have a significant effect on its audience. The look, feel and impact of text known as style attribute and interaction between colour and images displayed on the billboard largely do not drive sufficient emotional responses. In effect the design does not promote effective communication.

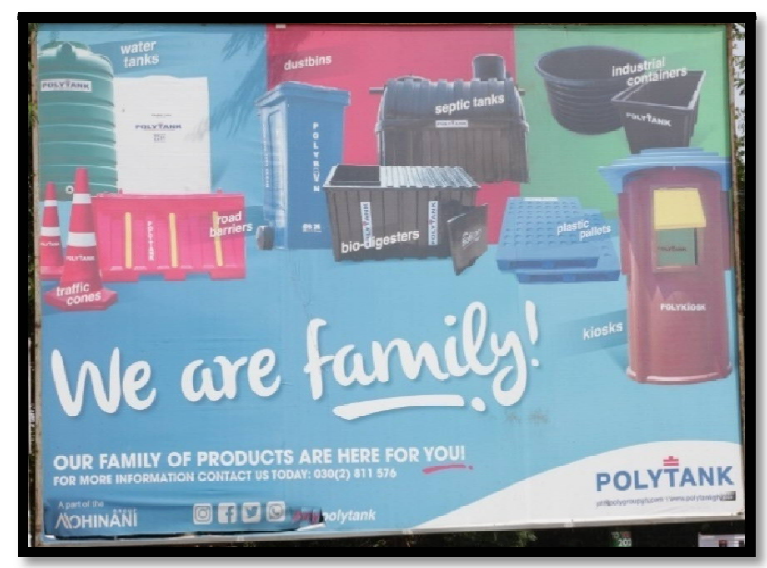

Figure 8: Poor Arrangement of Typography Photo Source: Researchers' Field Study, 2019

\subsubsection{Relationship between Typography, Colour and Image}

One attribute observed to have direct impact on visual perception and emotional responses to typography in advertising was the relationship between typography, colour and image. It is worth noting that the manipulation of typography, colour and image were visually appealing and ensured that the message content of every communication design product is effectively disseminated. This observation buttresses Barry (2005) submission that a good use of type in a graphic design work attracts a reasonable amount of appreciation which is characterised by perception. Sayegh (2018) 
emphasised that emotional responses of the audiences are based on the interaction between colour, type and mark. Sayegh continued that when the right thought is given to the psychology behind the design, the best work which tends to come out are essential. Fig. 9 projects a giant piece of billboard with gradient use of red, white and little black and green for the typefaces. The billboard displays a stylish font 'Iele' in green colour with white outline against pure red background with white outline. The typeface 'Thai Jasmine Long Grain Fragrant Rice' is captured beneath the stylish font 'lele'. In the centre of the billboard lies an image of a plate containing a garnished cooked 'lele' rice on a white background with the inscription 'Tasty food... Happy family'. It is crowned with an image of bagged 'lele' rice besides giving the billboard a good relationship between typography, colour and image to convey a message. The placement and relationship between typography, colour and images in the composition have compromised with readability making the billboard design as effective and visually appealing.

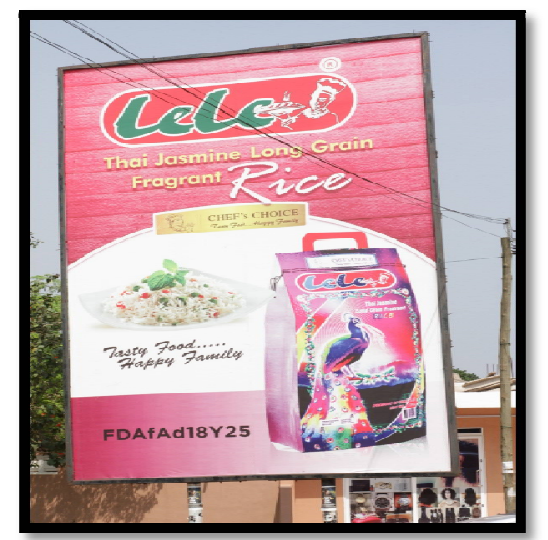

Figure 9: Good Relationship between Typography, Colour and Image to Convey a Message

Photo Source: Researchers' Field Study, 2019

\subsubsection{Basic Typography Principles of Tracking, Kerning and Leading}

The study revealed that graphic designers often rely on basic principles of tracking, kerning and leading in typography as design mechanisms to draw attention or attract the feelings of individuals in terms of theme and mood in print advertisement. The finding supports Evok's (2019) views on the art of arranging and designing type for advertising. Evok emphasised that the arrangement of type involves the selection of typefaces, point size, line length, line spacing (leading), adjustment of space between groups of letters (tracking) and adjustment of space between pairs of letters (kerning). Similarly, it was observed that bold, large text combined with efficient use of colour, shapes and images was used to draw attention to a particular advertisement to convey a particular message to the reader. However, designs that ignored some of the aforementioned design mechanisms rendered their communication ineffective. For example, in Fig. 10 the poster demonstrates typography, images and colour effectively, however, the basic typography principles of tracking, kerning and leading as seen at the bottom part of the design lacks these design mechanisms and makes the content difficult to be read.

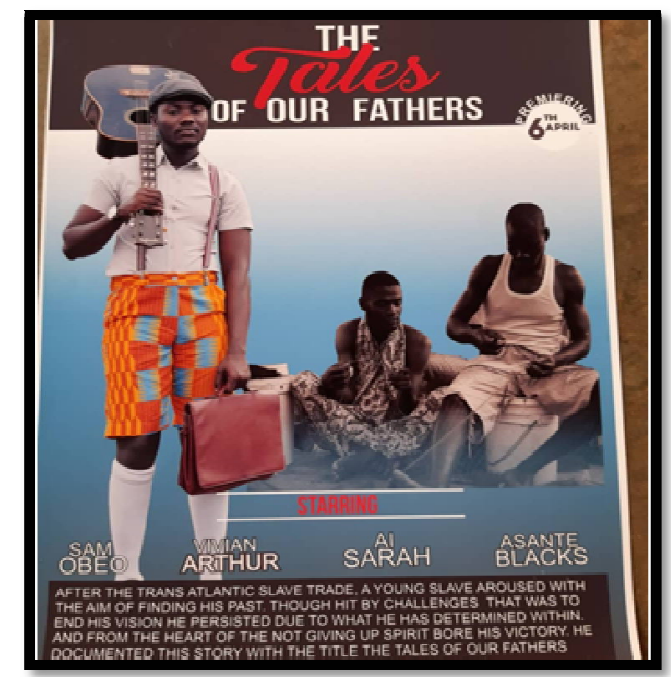

Figure 10: A Poster Lacking Tracking and Kerning

Photo Source: Researchers' Field Study, 2019

\subsubsection{The Emotion and Personality Trait of Fonts and Colour in Typography}

The results showed that fonts, colour and shapes seemed to be the elements that are needed to elicit an emotional response toward an advertising and design. This observation supports Bernazzani's (2017) findings when he posited that 
fonts are intriguing elements and identified serif, sans serif, script and modern fonts to have some peculiar positive or negative personality associations to influence emotions. Similarly, Waggener (2018) indicated that colours provide a positive and negative influence with a significant effect on typography. The study revealed that the impulse, sense of attraction and emotions on typography in advertising and design were based on colour and fonts and were the main reasons or attributes one could perceive and understand the message content of an advertisement. In Figure 11 the colours, as provided, formed integral parts of typography in the design and, not only do they convey emotional or personality responses but they also reinforce the values in the work of design. From an artistic point of view, this enables the typeface and its layouts to become more efficient and pronounced in terms of background colours. The unique features of the sans serif fonts characterised with its colours and varied sizes evoke the sense of 'stability and formality' in the design.

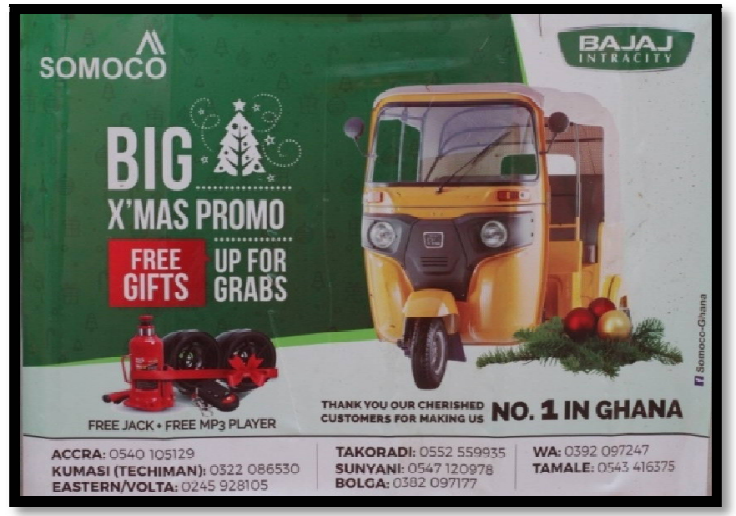

Figure 11: Fonts and Colours as Reinforce Values in Typography Photo Source: Researchers' Field Study, 2019

\subsubsection{Mismatch of Typography}

The findings revealed mismatch of typography or improper combination of typefaces, images and colours which do not harmonise and appeal to the emotions and perception of the viewer. This adversely distracts attention and does not enhance reader comfort and effective communication. A sample is the poster labelled Fig. 12 which is composed of images and texts on a gradient background colour of grayscale. The text 'Tales of Our Fathers' is seen not to harmonise well but as a font clash which distracts attention and takes away the content of the design and, in effect, prevents effective communication of the message. Aesthetically, the poster lacks a proper combination of typefaces, images and colours as part of achieving good typography basics, part practice, part personal preference and part intuition. Similarly, the size and colour of the typeface 'April' are completely a mismatch as it competes with the typeface 'Tales of Our Fathers'. It is noticed that the designer did not develop a sense of pairing fonts effectively for good harmonisation of the design elements which is important for easy reading and comprehension. McLeod (2008) and Gregroy (1970) reiterate that for one to comprehend easily the core concept of typography, it is important to read or absorb the writing as a whole rather than isolating the type or words individually. Barry (2005) affirmed that the eyes and brain play a large role in understanding, collecting visual information through the eyes and then seamlessly interpreted by the brain, letting the brain to unconsciously absorb emotionally in communicating messages through visual media. It is hoped the designer could have avoided this mismatch in typography or isolating of type by using fonts that harmonise well to give real communicative value to enhance understanding of the poster.

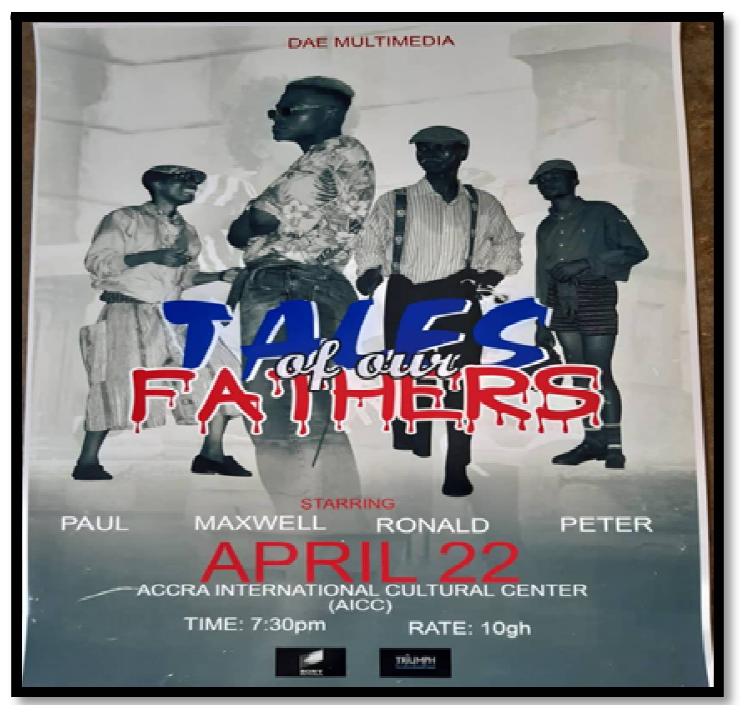

Figure 12: Mismatch of typography

Photo Source: Researchers' Field Study, 2019 


\section{Conclusions}

The study is a clear manifestation that the role of typography in creating advertisements is very important. In advertising, creating a positive viewer perception of print media advertisement begins with its typography which acts as the first line of communication. Typography is therefore considered to be a crucial element of graphic design that contributes to the overarching beauty of visual communication. Evidence gathered from the study infers that the effective use of typography by and large communicates meanings of the words the typeface represent and even sets a mood or elicit an emotion from the print advertisement. Similarly, the effective use of typography helps to draw attention to a particular advertisement and also convey a particular message to the viewer with efficient use of colours, shapes and images.

In conclusion, the researchers need to stress that typography is a valid discipline with basic rules, principles and parameters to follow, rather than any blind and unacceptable application when designing to enhance effective communication in print media advertising. The evidence from the study affirms that the determining guidelinesthat make typography most effective include the right selection, skilful and efficient use of fonts, point size, colours, shapes and images. Similarly, using a pleasing layout, creating an information hierarchy, applying colour psychology to the advertising design and enhancing readabilityare all crucial pieces of the puzzle when creating an outdoor advertising media for effective communication. However, the findings revealed that in print media advertisement when designers resort to making decisions on typography and do not adhere to the basic rules and guidelines for designing it has a negative impact on the use of typography for effective communication. On the other hand, when an outdooradvertising mediadesign adhere to the basic rules and guidelines for designing and has a good use of typography with dynamic and pleasing layout, it attracts attention, a reasonable amount of appreciation from the audience and promotes effective communication. This happens because the overall design holds the viewer's gaze until the message has been communicated.

\section{Recommendations}

It is recommended that contemporary graphic designers should explore and understand innovative mechanisms and basic principles for typographic design when developing print media advertisement for outdoor display. The designers should manage the use of typography in terms of theme and mood in an advertisement based on basic principles of arrangement which involves the selection of typefaces, point size, line length, line spacing (leading), adjustment of space between groups of letters (tracking) and adjustment of space between pairs of letters (kerning). This will help designers to use typography effectively to draw attention of the viewer to a particular advertisement and also convey a particular message.

Contemporary graphic designers should consider the use of dynamic and pleasing layoutwhen developing an advertising design for outdoor display. The format of the design which is the general arrangement of the wording and illustration in relation to the background must be attractive to influence the viewer and also must communicate its message within reasonable seconds.

When creating a print media advertisement, designers should make sure the text is legible to enhance readability. The right typography and the right font design that is easy to read both from close-up and far away should be chosen and used. This means the font size should be appropriate so that people can read the message from a good distance clearly. Too large of a font may overwhelm the design and consequently the message. Too small of a font size almost guarantees the information will be overlooked. This requires a search for the perfect balance of size for the design. To further enhance the readability, the font colour should be in contrast to the background colour. Therefore, a font colour that comes with both value and intensity contrast should be chosen.

It is also essential to consider usingclear and relevant images to convey the message. This is usually what will draw a person to the advertising design. The most striking images are typically simple, dramatic and inviting. Apply bold colours that allow the message to stand out against the background and bring the viewer's eyes right to the advertisement. It is worth noting that understanding colour psychology and applying it to the advertising design is an easy way to make the advertisement stand out in the marketplace and create a consumer connection. Graphic designers should therefore learn more about the feelings each colour represents and utilise them efficiently to appeal to viewer's emotions in their advertising designs.

Designers should also consider creating an information hierarchy in their designs. Certain elements on the advertisement obviously demand prominence hence, care must be taken to decide how and where to place or display them to enhance effective communication. Using different font sizes to show the hierarchy of importance is recommended. The most important words or phrases should be the largest in display.

\section{References}

i. Ambrose, G. \& Harris, P. (2008). Basics design 07: Grids. Lausanna, Switzerland: AVA Publishing.

ii. Ambrose, G. \& Harris, P. (2010). The visual dictionary of typography. New Jersey: John Wiley \& Sons, Inc.

iii. Ambrose, G. \& Harris, P. (2011). The fundamentals of typography. Lausanne, Switzerland: AVA Publishing.

iv. Art Times. (2014). What is typography and its role in design. http://www.theartimes.com/what-is-typography/ (Retrieved August 14, 2019).

v. Barry, A. M. (2005). Perception theory. In K. Smith, S. Moriarty, G. Barbatsis, \& K. Kenney (Eds.), Handbook of visual communication. Theory, methods and media (p. 45). Mahwah, New Jersey: Lawrence Erlbaum Associates, Inc.

vi. Bernazzani, S. (2017). Fonts \& feelings: Does typography connote emotions? https://blog.hubspot.com/marketing/typography-emotions(Retrieved January 10, 2019).

vii. Best, J. W. (1981). Research in Education. New Jersey: Prentice Hall. 
viii. Birkner, J. (2018). Typeface. http://parrybrandinggroup.com/vocabulary/typeface/(Retrieved January 10, 2019).

ix. Brumberger, E. R. (2003). The rhetoric of typography: The awareness and impact of typeface appropriateness. Technical communication, 50, 224.

x. Chapman, C. (2019). A crash course in typography: The basics of type. https://www.jotform.com/blog/a-crashcourse-in-typography-the-basics-of-type/ (Retrieved January 10, 2020).

xi. Childers, T. L. \& Jass, J. (2002). All dressed up with something to say: Effects of typeface semantic associations on brand perceptions and consumer memory. Journal of Consumer Psychology. 12 (2).

xii. Creswell, John W. (2007). Educational research: Planning, conducting, and evaluating quantitative and qualitative research - 4th ed. Boston; Pearson Education, Inc.,

xiii. Darwish, A. (2010). A Journalist's guide to live, direct and unbiased news translation. Melbourne: Writescope Pty Ltd.

xiv. El Sayegh, A. M. (2018). The aesthetics impact of the typographic on the logo advertising and meaning (Analytical research). IOSR Journal of Research \& Method in Education, Vol 8, Issue 2 Ver.V pp 18-28

xv. Evok advertising. (2019). Typography: A vital component in the world of advertising. https://www.evokad.com/typography-a-vital-component-in-the-world-of-advertising/ (Retrieved January 15, 2019)

xvi. Graphic composition (2017). The importance of typography in graphic design.

https://www.graphiccomp.com/post/ the-importance-of-typography-in-graphic-design (Retrieved December 24, 2019).

xvii. Gregory, R. (1970). The intelligent eye. London: Weidenfeld and Nicolson

xviii. Guthrie, K. L. (2009). Emotional response to typography: The role of typographic variations in emotional response to advertising (Master's thesis). Graduate school of the University of Florida.

xix. Harkins, M. (2011). Basics typography: Using type. Lausanne, Switzerland: AVA Publishing SA

xx. Knight, C. \& Glaser, J. (2012). When typography speaks louder than words.

https://www.smashingmagazine.com/when-typography-speaks-louder-than-words/ (Retrieved January 15, 2019).

xxi. Koch, B. E. (2011). Human emotion response to typographic design (Doctoral thesis). Faculty of the Graduate School,University Of Minnesota, Canada.

xxii. Leedy, P.D. \& Ormrod, J.E. (2005). Practical research: Planning and Design. New Jersey. Prentice Hall

xxiii. Lynch, J. P. \& Horton, S. (2019). Typography. https://webstyleguide.com/9-typography.html (Retrieved January $14,2020)$.

xxiv. Mark, J. J. (2011). Writing. Retrieved fromwww.ancient.eu/writing/(Retrieved April 12, 2019)

xxv. McCarthy, M. S. \& Mothersbaugh, D. L. (2002). Effects of typographic factors in advertising -based persuasion. A general model and initial empirical tests. Psychology \& Marketing. 19, 663-691.http://onlinelibrary.wiley.com (Retrieved October 12, 2019).

xxvi. McLeod, S. (2008). Visual perception theory. https://www.simplypsychology.org/perception-theories.html (Retrieved April 28, 2019).

xxvii. Nikolov, A. (2017). Design principle: Aesthetics. The power of beauty in design. https://uxdesign.cc/designprinciple-aesthetics-af926f8f86fe(Retrieved April 15, 2019)

xxviii. Purely Branded. (2019). The impact of typography on web design and brand messaging. https://www.purelybranded.com/insights/the-impact-of-typography-on-web-design-and-brand-messaging/ (Retrieved, April 12, 2019)

xxix. Ovsyannykov, I. (2018). 20 Typography rules every designer should know. https://creativemarket.com/blog/typography-rules(Retrieved December 26, 2019)

xxx. Scarborough, S. (2015). Legibility and readability. http://osw_ego.edu/ sscarbor/typography/ (Retrieved April 17, 2019)

xxxi. Schriver, K. (1997). Dynamics in document design. New York: John Wiley \& Sons, Inc.

xxxii. Squire, V., Forssman, F., \& Willberg, H. P. (2006). Getting it right with type: The dos and don'ts of typography.

xxxiii. London, UK: Laurence King Publishing Ltd

xxxiv. Thorlacius, L. (2007). The role of aesthetics in web design. Nordicom Review 28 (2007) 1, pp. 63-76. https://www.popwebdesign.net/popart_blog/pdf/The_Role_of_Aesthetics_in_Web_Design.pdf (Retrieved April 27, 2019).

xxxv. Waggener, J. (2018). Why color and typography are critical to your brand [Infographic].

https://www.impactbnd.com/blog/why-color-and-typography-are-critical-to-your-brand-infographic (Retrieved April 27, 2019). 